\title{
Bronchial angiogenesis in severe glucocorticoid-dependent asthma
}

\author{
B. Vrugt*, S. Wilson ${ }^{\#}$, A. Bron*, S.T. Holgate ${ }^{\#}$, R. Djukanovic ${ }^{\#}$, R. Aalbers ${ }^{\#}$
}

Bronchial angiogenesis in severe glucocorticoid-dependent asthma. B. Vrugt, S. Wilson, A. Bron, S.T. Holgate, R. Djukanovic, R. Aalbers. C ERS Journals Ltd 2000.

ABSTRACT: To examine the role of the bronchial microvasculature and adhesion molecule expression in severe asthma, the authors have performed an immunohistochemical study on bronchial biopsies comparing 15 glucocorticoid-dependent asthmatics, 15 mild asthmatics and eight control subjects.

Serially cut glycol methacrylate-embedded sections were stained with monoclonal antibodies identifying the vessel marker $\mathrm{EN}-4$, intercellular adhesion molecule (ICAM)-1, vascular cell adhesion molecule (VCAM)-1, E- and P-selectin. Sections were also stained for lymphocyte function associated antigen (LFA)-1 and very late antigen (VLA)-4.

By comparison with mild asthma and nonasthma, severe asthma was characterized by increased numbers of submucosal vessels $(p=0.009)$ which was associated with increased numbers of vessels expressing ICAM-1 $(p=0.005)$. A highly significant correlation was found between the total number of $\mathrm{EN}-4+$ vessels and the vessels expressing ICAM-1 $(\mathrm{r}=\mathbf{0 . 8 5}, \mathrm{p}=\mathbf{0 . 0 1})$. In contrast, $\mathrm{E}$-selectin expression was lower in severe as compared with mild asthma $(p=0.01)$ but not different from normal. No differences were found between the three groups in the expression of VCAM-1 and Pselectin nor in numbers of LFA-1+ and VLA-4+ cells.

The results of this study support the notion that mucosal neovascularization is an important feature of airways remodelling in severe asthma. This is associated with a relatively higher density of vessels expressing intercellular adhesion molecule-1, although the expression of this adhesion molecule per vessel was not raised.

Eur Respir J 2000; 15: 1014-1021.
*Dutch Asthma Centre, Davos, Switzer-
land. "Southampton University, Southampton, UK.

Correspondence: B. Vrugt

Martini Hospital Groningen

Pathology Department

P.O. Box 30033

9700 RM Groningen

The Netherlands

Fax: 31505246758

Keywords: Adhesion molecule angiogenesis

severe asthma

Received: February 21999

Accepted after revision February 132000
The immunopathology of asthma is characterized by accumulation of eosinophils and mononuclear cells in the submucosa, and is associated with sloughing of epithelial cells, smooth muscle hypertrophy and hyperplasia, goblet cell metaplasia, and subepithelial collagen deposition, which can result in permanent thickening and remod elling of the airways $[1,2]$. This may give rise to an irreversible component of bronchial obstruction and ex plain the persistent airflow limitation observed in patients with poorly-controlled asthma [3].

Vascular dilatation and increased vascularity have been described in patients who died from fatal asthma [4-6]. The pathophysiological implications of these changes as components of airway remodelling of living patients with chronic severe asthma are not fully understood. Plasma exudation and vascular congestion are induced by various mediators, such as histamine and sulfidopeptide leukotrienes, known to be released in asthma, and may contribute to the acute airway obstruction observed in asthmatic subjects following allergen exposition $[1,4]$.

In asthma, the bronchial circulation is not only involved in oedema formation, but also participates in the recruitment of leukocytes through the expression of various vascular adhesion molecules $[7,8]$. In the adhesion cascade leukocyte adhesion is believed to be mediated by selectins (P-selectin and E-selectin) which promote leukocyte rolling and attachment to the endothelium. This is follow- ed by adhesion through the interaction between integrins expressed on leukocytes and intercellular adhesion molecule (ICAM)-1 and vascular cell adhesion molecule (VCAM)-1 expressed on the endothelium. Studies on bronchial biopsy specimens obtained from mild asthmatics have demonstrated constitutive expression of ICAM-1 and, to a lesser extent, E-selectin on the bronchial microvasculature, which was not significantly different from normal subjects $[9,10]$. The authors have recently demonstrated an increase in the number of T-cells expressing the activation marker CD25 (interleukin (IL)-2 receptor) in bronchial biopsies from clinically unstable glucocorticoid-dependent asthmatics in comparison to mild asthmatics and normals [11]. However, this was not associated with raised eosinophil counts possibly secondary to the immunosuppressive actions of glucocorticoids. From these observations it was concluded that in severe asthma additional factors, such as airways remodelling, may play a more important role in the clinical presentation of the disease, and that the recruitment of various inflammatory cells may be differentially regulated because of differences in adhesive interactions between leukocytes and the endothelium.

Histological examination of biopsies from mild asthmatics obtained during bronchoscopy [12] and bronchial tissue in postmortem studies of asthma death $[5,6]$ have highlighted the presence of increased submucosal vessel 
density as well as an increase in submucosal vascular volume when compared to nonasthmatic control subjects. It was hypothesized that increased vascularity is also present in the airways of severe asthmatics. In previous studies it has been demonstrated that the adherence of activated T-cells depends on ICAM-1/lymphocyte function associated antigen (LFA)-1 and VCAM-1/very late antigen (VLA)-4 interaction, whereas the attachment of eosinophils results from the interaction between VLA-4 and VCAM-1. It was therefore hypothesized that the increased mucosal T-cell activation without a significant eosinophilia may be attributable to an increased expression of ICAM-1, but not VCAM-1 on the endothelium. To examine these issues the authors have investigated by immunohistochemistry the density of the submucosal vascular bed and the expression of adhesion molecules in endobronchial biopsies obtained from severe glucocorticoid-dependent asthmatics, and have compared the results with those from mild asthmatics and healthy control subjects.

\section{Subjects and methods}

\section{Subjects}

Fifteen subjects with chronic severe asthma (median age 31 yrs (range 13-66)), 15 mild atopic asthmatics (median age 22 yrs (range 19-39)) and eight nonatopic, healthy control subjects (median age 29 yrs (range 21-50)) were studied. Asthma was defined according to the standards of the American Thoracic Society [13] and the severity scored according to WoOLCOCK [14]. In all the severe asthmatics atopy was confirmed by positive skin tests to two or more common aeroallergens, increased total immunoglobulin $(\mathrm{Ig}) \mathrm{E}$, and/or positive radioallergosorbent test. None of the studied individuals had ever smoked or experienced respiratory infection within 6 weeks prior to bronchoscopy.

All the severe asthmatics (table 1) were patients referred to the Dutch Asthma Centre in Davos (Switzerland) be- cause of unsatisfactory control of their asthma, with frequent exacerbations for which hospital admissions and administration of high doses of glucocorticoids were required. Each subject was followed closely after admission during at least 3 months for the presence of unidentified allergies and potential aggravating factors (gastro-oesophageal reflux, obstructive sleep apnoea, hyperventilation, drug intolerance, sinusitis and treatment compliance). In contrast to the mild asthmatics, all the severe asthmatic subjects had frequent nocturnal symptoms characterized by awakening with dyspnoea and/or wheezing at the time of study. All attempts to reduce the dose of glucocorticoids resulted in increased symptoms, variability in peak expiratory flow (PEF), and decrease in forced expiratory volume (FEV1).

Mild atopic asthmatics and healthy nonatopic control subjects were studied in Southampton, UK for comparison using the same methods (table 2). These asthmatics were treated as required with low doses of $\beta_{2}$-agonists only and had not received inhaled or systemic glucocorticoids for at least 2 months prior to bronchoscopy.

The study was approved by the Ethics Committee of the Dutch Asthma Centre (Switzerland) and the Southampton Hospital and University Ethics Committee (UK), and all subjects gave their written informed consent.

\section{Clinical and physiological measurements}

Asthma severity was assessed during a 2-week period preceding bronchoscopy as previously described [14]. A total clinical severity score was given based on a combination of symptom scores, frequency of bronchodilator use, and variability in PEF, each ranging 0-4. Subjects were asked to record daily asthma symptoms on a diary card using a $0-3$ score $(0=$ no symptoms, $1=$ mild, $2=$ moderate, $3=$ severe). A total of six respiratory symptoms were recorded: nocturnal dyspnoea, nocturnal coughing, wheezing and coughing during the day, sputum production, and the effect of the asthma on daily activities. The

Table 1. - Subjects characteristics:severe asthmatics

\begin{tabular}{|c|c|c|c|c|c|c|c|c|}
\hline $\begin{array}{l}\text { Subject } \\
\text { No. }\end{array}$ & $\begin{array}{l}\text { FEV1 } \\
\% \text { pred }\end{array}$ & $\begin{array}{l}\% \text { PEF } \\
\text { var }\end{array}$ & $\begin{array}{l}\text { Salbutamol } \\
\text { No. inhalations } \cdot \text { day }^{-1}\end{array}$ & $\begin{array}{l}\text { Symptom } \\
\text { score }\end{array}$ & $\begin{array}{l}\text { Total } \\
\text { score }\end{array}$ & $\begin{array}{l}\operatorname{IgE} \\
\mathrm{IU} \cdot \mathrm{L}^{-1}\end{array}$ & $\begin{array}{l}\text { Inhaled GCS mg } \\
\text { inhaled } \cdot \text { day }^{-1}\end{array}$ & $\begin{array}{c}\text { Oral GCS } \\
\text { mg orally } \cdot \text { day }^{-1}\end{array}$ \\
\hline 1 & 68 & 31.6 & 10 & 7.3 & 12 & 156 & 2 & 100 \\
\hline 2 & 91 & 26.7 & 8 & 6.9 & 12 & 126 & 2 & 60 \\
\hline 3 & 82 & 64.1 & 7 & 4.7 & 12 & 72 & 4 & 35 \\
\hline 4 & 53 & 21.4 & 7 & 5.7 & 10 & 1168 & 2 & 60 \\
\hline 5 & 74 & 26.6 & 8 & 5.6 & 12 & 361 & 4 & 50 \\
\hline 6 & 77 & 20.4 & 14 & 11.1 & 12 & 42 & 4 & 50 \\
\hline 7 & 93 & 52.2 & 10 & 8.9 & 12 & 2735 & 2.4 & 90 \\
\hline 8 & 40 & 21.4 & 8 & 4.9 & 12 & 1078 & 2 & 75 \\
\hline 9 & 87 & 17.8 & 6 & 1.7 & 9 & 2000 & 2.4 & 5 \\
\hline 10 & 96 & 26.0 & 6 & 3.1 & 12 & 53 & 2.4 & 5 \\
\hline 11 & 95 & 21.9 & 5 & 4 & 11 & 869 & 3 & 5 \\
\hline 12 & 86 & 20.7 & 7 & 7.6 & 12 & 104 & 2 & 12.5 \\
\hline 13 & 71 & 16.4 & 6 & 5.1 & 10 & 150 & 3.2 & 2.5 \\
\hline 14 & 67 & 22.2 & 4 & 4.6 & 10 & 6 & 4 & 7.5 \\
\hline 15 & 56 & 18.9 & 7 & 13 & 11 & 63 & 4 & 40 \\
\hline Mean \pm SD & $75 \pm 16.7$ & $27.2 \pm 13.3$ & & & & & & \\
\hline $\begin{array}{l}\text { Median } \\
\text { (range) }\end{array}$ & & & $\begin{array}{c}7 \\
(4-14)\end{array}$ & $\begin{array}{c}5.6 \\
(1.7-13)\end{array}$ & $\begin{array}{c}12 \\
(9-12)\end{array}$ & $\begin{array}{c}150 \\
(6-2735)\end{array}$ & $\begin{array}{c}2.4 \\
(2-4)\end{array}$ & $\begin{array}{c}40 \\
(2.5-100)\end{array}$ \\
\hline
\end{tabular}

FEV1: forced expiratory volume in one second; \% pred: percentage of predicted; PEF: peak expiratory flow; var: variability; IgE: immunoglobulin E; GCS: glucocorticoids. 
Table 2. - Subjects characteristics:mild asthmatics

\begin{tabular}{|c|c|c|c|c|c|c|c|c|}
\hline $\begin{array}{l}\text { Subject } \\
\text { No. }\end{array}$ & $\begin{array}{l}\text { FEV1 } \\
\% \text { pred }\end{array}$ & $\begin{array}{c}\% \text { PEF } \\
\text { var }\end{array}$ & $\begin{array}{c}\quad \text { Salbutamol } \\
\text { No. inhalations } \cdot \text { day }^{-1}\end{array}$ & $\begin{array}{l}\text { Symptom } \\
\text { score }\end{array}$ & $\begin{array}{l}\text { Total } \\
\text { score }\end{array}$ & $\begin{array}{l}\operatorname{IgE} \\
\mathrm{IU}^{-} \mathrm{L}^{-1}\end{array}$ & $\begin{array}{l}\text { Inhaled GCS } \\
\text { mg inhaled } \cdot \text { day }^{-1}\end{array}$ & $\begin{array}{c}\text { Oral GCS } \\
\text { mg orally } \cdot \text { day }^{-1}\end{array}$ \\
\hline 1 & 114 & 5 & 0 & 0.8 & 2 & 264 & 0 & 0 \\
\hline 2 & 80 & 23.4 & 0 & 3.8 & 6 & 1980 & 0 & 0 \\
\hline 3 & 106 & 15 & 5 & 2.1 & 8 & 91 & 0 & 0 \\
\hline 4 & 120 & 4.2 & 0 & 2.4 & 1 & 123 & 0 & 0 \\
\hline 5 & 122 & 1.6 & 0 & 0.7 & 1 & 227 & 0 & 0 \\
\hline 6 & 127 & 6.7 & 1 & 2.7 & 5 & 152 & 0 & 0 \\
\hline 7 & 80 & 10.2 & 2 & 1.1 & 5 & 217 & 0 & 0 \\
\hline 8 & 107 & 9 & 1 & 1.0 & 5 & 360 & 0 & 0 \\
\hline 9 & 91 & 4 & 2 & 0.3 & 5 & 85 & 0 & 0 \\
\hline 10 & 100 & 11.7 & 3 & 0.6 & 5 & 110 & 0 & 0 \\
\hline 11 & 87 & 3.1 & 1 & 0.3 & 3 & 220 & 0 & 0 \\
\hline 12 & 76 & 11.1 & 2 & 1.3 & 6 & 430 & 0 & 0 \\
\hline 13 & 96 & 1.5 & 1 & 0.9 & 3 & 60 & 0 & 0 \\
\hline 14 & 103 & 7.3 & 1 & 0.5 & 4 & 750 & 0 & 0 \\
\hline 15 & 105 & 4.3 & 1 & 0.6 & 4 & 108 & 0 & 0 \\
\hline Mean \pm SD & $100 \pm 15.9$ & $7.9 \pm 5.8$ & & & & & & \\
\hline \multicolumn{2}{|c|}{ Median (range) } & & $1(0-5)$ & $0.9(0.3-3.8)$ & $5(1-8)$ & $217(60-1980)$ & & \\
\hline $\mathrm{p}$-value & 0.0002 & 0.0001 & 0.0001 & 0.0001 & 0.0001 & NS & & \\
\hline
\end{tabular}

FEV1: forced expiratory volume in one second; \% pred: percentage of predicted; PEF: peak expiratory flow; var: variability; IgE: immunoglobulin E; GCS: glucocorticoids; NS: nonsignificant.

mean of 14 daily asthma scores was calculated and used in the total score. All subjects recorded PEF rates twice daily before and after bronchodilator medication using a mini Wright peak flow meter (Airmed, London, UK). Variability in PEF, an indicator of airways irritability, was calculated by the difference between the maximum and minimum of the PEF readings each day and expressed as a percentage of the maximum [15]. The mean of 14 daily values was calculated and used in the total score. In addition, subjects were asked to record their daily use of salbutamol as the number of puffs and the frequency of nebulized salbutamol use. Prebronchodilator FEV1 was measured using either a pneumotachometer (Jaeger Masterlab, Würzburg, Germany) or a dry wedge spirometer (Vitalograph, Buckinghamshire, UK). The best of three readings was used for statistical analyses. Values were expressed as a percentage of predicted values [16].

\section{Fibreoptic bronchoscopy, tissue processing and immuno- histochemistry}

Fibreoptic bronchoscopy was undertaken according to previously published methods [17]. Biopsies were processed into glycol methacrylate (GMA) resin for immunohistochemistry, as previously described [18]. Semithin 2-mm sections were cut and immunostained using a streptavidine-biotin-peroxidase detection system with aminoethylcarbazole as a chromogen which produces a red reaction product.

To investigate the expression of adhesion molecules, serial sections were stained for ICAM-1 (CD54; Rothlein, Boehringer Ingelheim, Ridgefield, CT, USA), VCAM-1 (CD106; Serotec, Oxford, Oxfordshire, UK), E- and P-selectin (CD62E and CD62P; Coulter Electronics, Luton, Bedfordshire, UK) and the vessel marker EN-4 (Bradshaw Biologicals, Loughborough, Leicestershire, UK). Monoclonal antibodies were also employed to identify the ligands for ICAM- 1 and VCAM-1, the $\beta_{2}$-integrin LFA-1
(CD11a) and $\beta 1$-integrin VLA-4 (CD49d; Cymbus Bioscience Ltd, Southampton, UK) respectively.

All sections for each antibody were examined simultaneously by a blinded investigator (B. Vrugt). Only positively stained vessels and nucleated, positively stained cells were counted at $\times 40$ magnification. The area of the submucosa was measured using the Colourvision 1.6-4SR software package on a Macintosh computerized image analyser (Improvision, Birmingham, UK) excluding smooth muscle and glandular tissue. The total count of cells and the density of vessels were expressed as the mean number per square millimetre submucosa in two sections. The expression of endothelial adhesion molecules was shown as the total number of vessels staining positively for the adhesion molecules and percentage of total (EN-4+) vessels.

\section{Data analyses}

FEV1 was expressed as mean \pm SD per cent of predicted and PEF variability as mean \pm SD. Comparison of lung function results between groups was performed using the unpaired t-tests. As the immunohistochemical data were not normally distributed, the Kruskal-Wallis (K-W) test was used, and, if significant, further tested for significance using the Mann-Whitney U-test. A Bonferonni correction for multiple comparisons was applied by multiplying the obtained p-values by the number of tests performed. Correlations between histological findings and lung function parameters were sought by Spearman's rank correlation test. Differences were considered significant if $\mathrm{p}<0.05$.

\section{Results}

All bronchoscopies were performed without complications, and in no case was it necessary to terminate the procedure. 


\section{Clinical dato}

The results from the clinical data are summarized in tables 1 and 2 . Mean \pm SD morning PEF was significantly lower in the severe asthmatics $(64.7 \pm 20.6 \%)$ compared with mild asthmatics $(98.3 \pm 10.7 \%, \mathrm{p}=0.0001)$. Both the severe and mild asthmatics had significantly higher levels of IgE than the healthy control subjects ((median (range)) $\left.32.5 \mathrm{IU} \cdot \mathrm{L}^{-1},(10-75) \mathrm{K}-\mathrm{W}: \mathrm{p}=0.001\right)$.

\section{Immunohistochemistry}

The use of the EN-4 antibody detected mucosal vessels in all the biopsies, with the number of vessels being significantly higher in the severe asthmatics $\left(91.4 \cdot \mathrm{mm}^{-2}\right.$ submucosa) when compared to both the mild asthmatics $\left(47.7 \cdot \mathrm{mm}^{-2}\right.$ submucosa) and control subjects $\left(48.4 \cdot \mathrm{mm}^{-2}\right.$ submucosa), K-W: p=0.009, (fig. 1 and 2). Vessel numbers of two different submucosal areas within the same biopsy specimen showed a good repeatability with highly significant correlations being found in the overall group $\left(r_{s}=0.97, p=0.0001\right)$ and in the severe asthmatic group $\left(r_{\mathrm{s}}=0.95, \mathrm{p}=0.0004\right)$.

Expression of ICAM-1 was observed on the endothelium of the submucosal venules and, if present, also in the epithelium. In contrast VCAM-1, E- and P-selectin was only seen on blood vessels. The total number of vessels expressing ICAM-1 was significantly higher in the severe

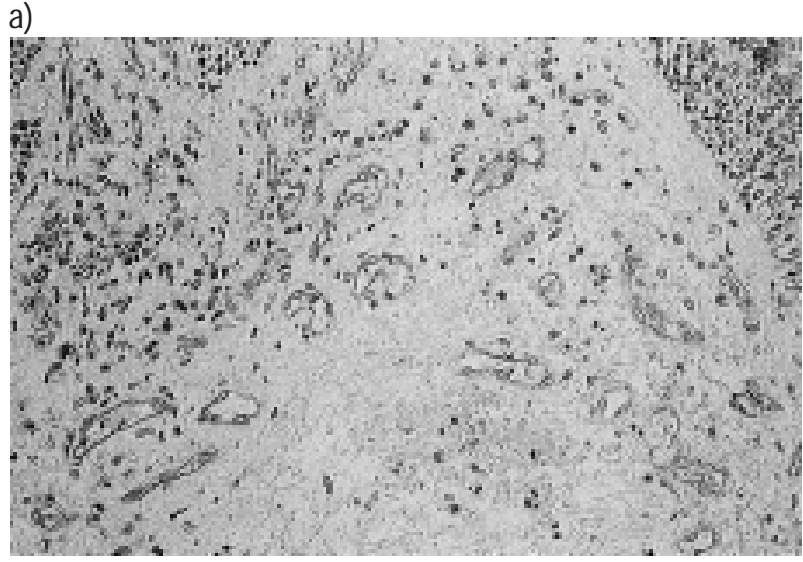

b)

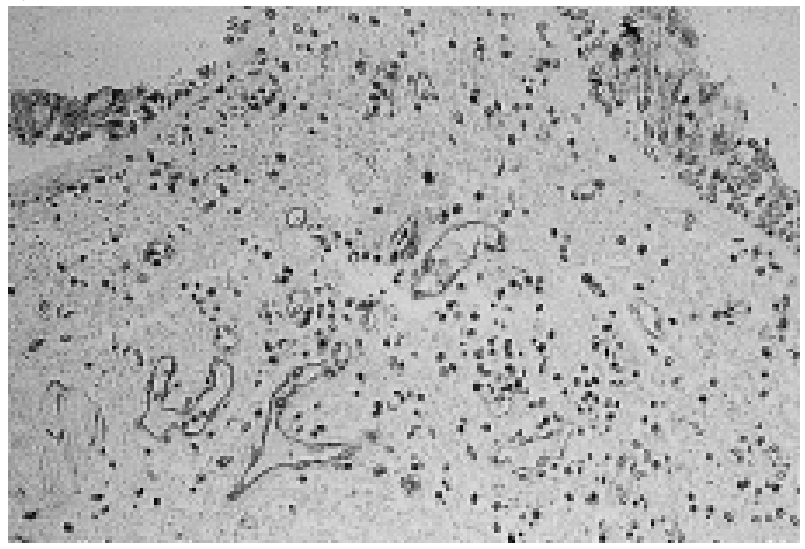

Fig. 1. - Bronchial biopsies showing immunostaining for the vessel marker EN-4 in a severe asthmatic (a) and mild asthmatic subject (b), respectively $(350 \times$ magnification).

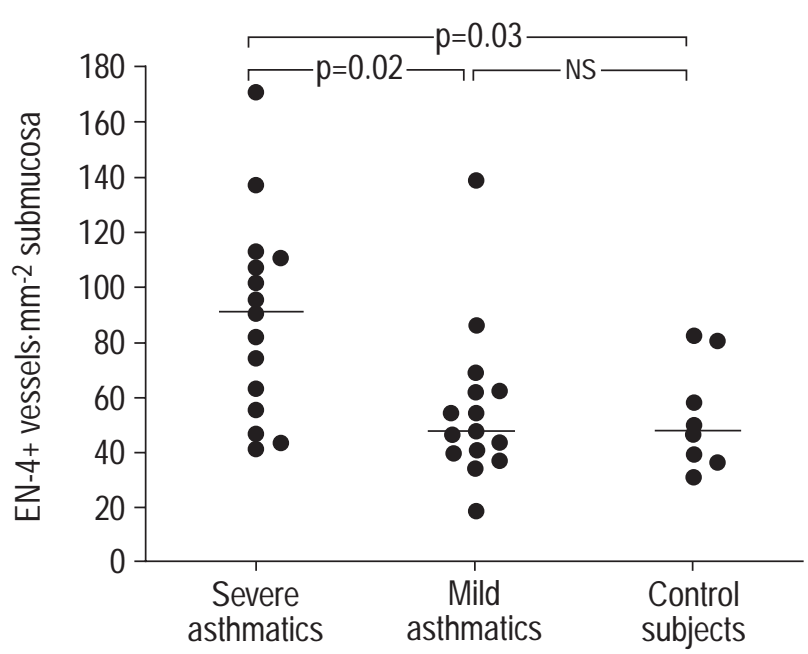

Fig. 2. - Density of the subepithelial microvasculature expressed as numbers of the vessel marker, EN-4+, vessels in the submucosa of severe asthmatics, mild asthmatics and healthy nonatopic control subjects. Comparison between groups was by Mann-Whitney U-test with Bonferroni's correction. Ns: nonsignificant.

asthmatics $\left(34.4 \cdot \mathrm{mm}^{-2}\right.$ submucosa) than in the mild asthmatics $\left(19.2 \cdot \mathrm{mm}^{-2}\right.$ submucosa) and control subjects (15.1. $\mathrm{mm}^{-2}$ submucosa, K-W: $\mathrm{p}=0.005$; fig. 3a). The percentage of ICAM-1 expression was not significantly different between the three groups: $38.4 \%$ in the severe asthmatics, $36.1 \%$ in the mild asthmatics, and $30.2 \%$ in the control subjects (K-W: $p=0.20$; fig. $3 b$ ). No significant differences were found in the percentage or the total number of vessels expressing VCAM-1: median (range) 2.1 (0$18.8) \%$ and $1.2 \cdot \mathrm{mm}^{-2}$ submucosa $(0-20.8)$ in the severe asthmatics, $2.7(0-13.4) \%$ and $1.2 \cdot \mathrm{mm}^{-2}$ submucosa $(0$ 18.6) in the mild asthmatics, and $1.2(0-6.1) \%$ and 0.7 . $\mathrm{mm}^{-2}$ submucosa $(0-3.1)$ in the control subjects $(\mathrm{K}-\mathrm{W}$ : $\mathrm{p}=0.23$ and 0.30 , respectively). Similarly, no differences were seen in the percentage or total numbers of P-selectin+ vessels $\left(13.3(4.8-41.5) \%\right.$ and $11.0 \cdot \mathrm{mm}^{-2}$ submucosa (2.6-23.2)) in the severe asthmatics, $10.4(0.9-49.5) \%$ and $7.6 \cdot \mathrm{mm}^{-2}$ submucosa $(0.6-33.9)$ in the mild asthmatics, and $18.9(10.3-31.0) \%$ and $8.4 \cdot \mathrm{mm}^{-2}$ submucosa (4.3-24.5) in the control subjects $(\mathrm{K}-\mathrm{W}: \mathrm{p}=0.19$ and $\mathrm{p}=$ 0.09 , respectively). In contrast, the total number of vessels expressing E-selectin was lower in the severe asthmatics $\left(7.9 \cdot \mathrm{mm}^{-2}\right.$ submucosa) as compared with mild asthmatics $\left(14.1 \cdot \mathrm{mm}^{-2}\right.$ submucosa) but not different from normal (12.4. $\mathrm{mm}^{-2}$ submucosa, K-W: $\mathrm{p}=0.045$; (fig. 4a). A significant lower percentage of E-selectin+ vessels was seen in the severe asthmatics $(7.4 \%)$ when compared with the mild asthmatics $(26.5 \%)$ and control subjects $(22.9 \%)$, $\mathrm{K}-\mathrm{W}: \mathrm{p}=0.0005$ (fig. 4b).

No significant differences were found in the median (range) number of LFA-1+ cells per square millimetre of submucosa between the severe asthmatics (34.7 (8.2$153)$ ), the mild asthmatics (65.2 (21.2-193)), and the control subjects $(30.7(18.6-111.8)), \mathrm{K}-\mathrm{W}: \mathrm{p}=0.11$. Similarly, the numbers of VLA-4+ cells were not significantly different between the severe asthmatics $\left(11.3 \cdot \mathrm{mm}^{-2}\right.$ submucosa (1.6-36.2)), the mild asthmatics $\left(9.6 \cdot \mathrm{mm}^{-2}\right.$ submucosa $(0.9-36.6))$, and the control subjects $\left(8.1 \cdot \mathrm{mm}^{-2}\right.$ submucosa $(1.9-10.2)), \mathrm{K}-\mathrm{W}: \mathrm{p}=0.17$. 

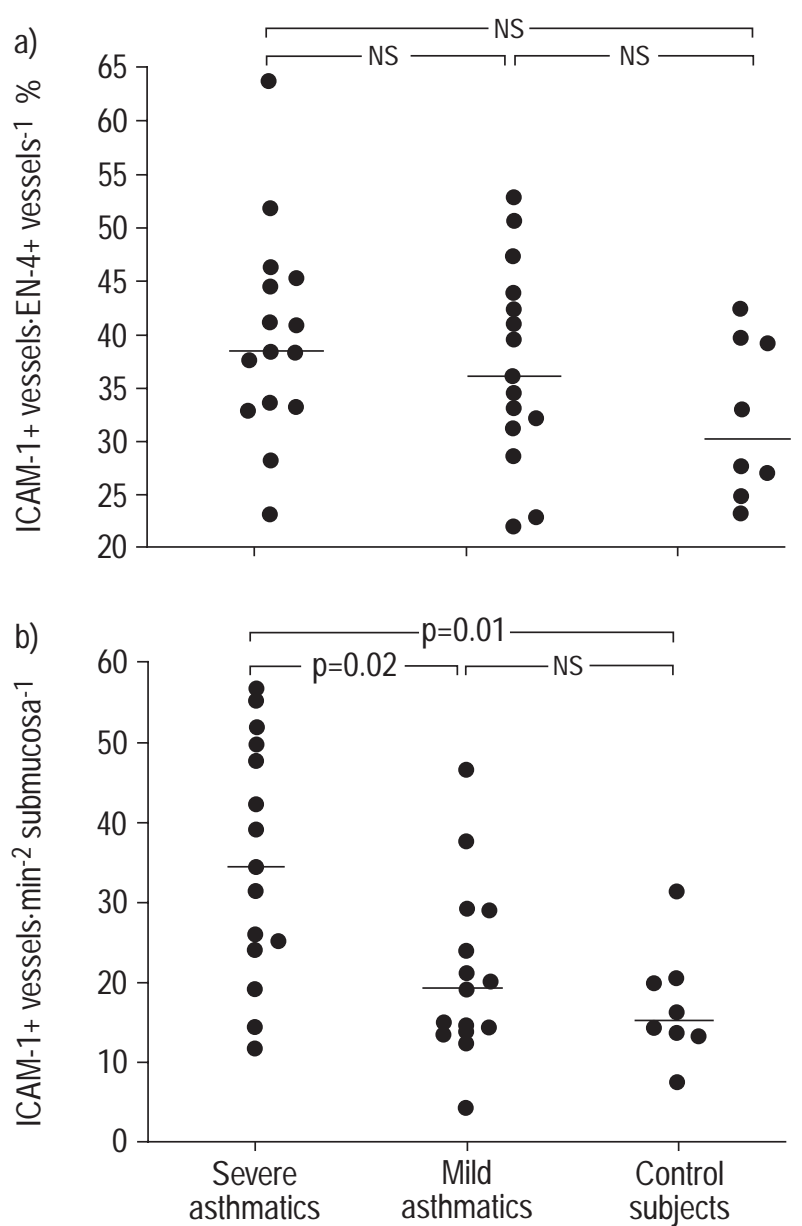

Fig. 3. - Intercellular adhesion molecule (ICAM)-1 expressed as percentage of the total number of the vessel marker, EN4+, vessels (a) and as number of ICAM-1+ vessels per square millimetre submucosa (b) in the biopsies of severe asthmatics, mild asthmatics and healthy nonatopic control subjects. Comparison between groups was by Mann-Whitney Utest with Bonferroni's correction. The horizontal lines represent the median values. Ns: nonsignificant.

In the severe asthmatic group a highly significant correlation was found between the total number of EN4+ vessels and the number of vessels expressing ICAM-1 $\left(r_{s}=0.85, p=0.001\right)$. An inverse correlation was also found between the mean morning PEF and the total number of vessels per square millimetre submucosa in biopsies from all asthmatics $\left(\mathrm{r}_{\mathrm{s}}=-0.69, \mathrm{p}=0.0002\right)$, the mild asthmatics $\left(r_{s}=-0.69, p=0.01\right)$ and the severe asthmatics $\left(r_{s}=-0.59, p=\right.$ 0.02 ). There was no significant correlation between FEV1 or any of the other clinical parameters and the number of vessels in the biopsies from the severe asthmatics ( $p>0.05)$.

\section{Discussion}

In this study the authors have presented several novel findings regarding the subepithelial microvasculature and expression of endothelial-associated adhesion molecules in the bronchial mucosa of severe glucocorticoid-dependent asthmatics. The authors have shown evidence of increased numbers of mucosal blood vessels as a feature of severe asthma which correlate with reduced morning PEF suggesting that angiogenesis may be an important determinant
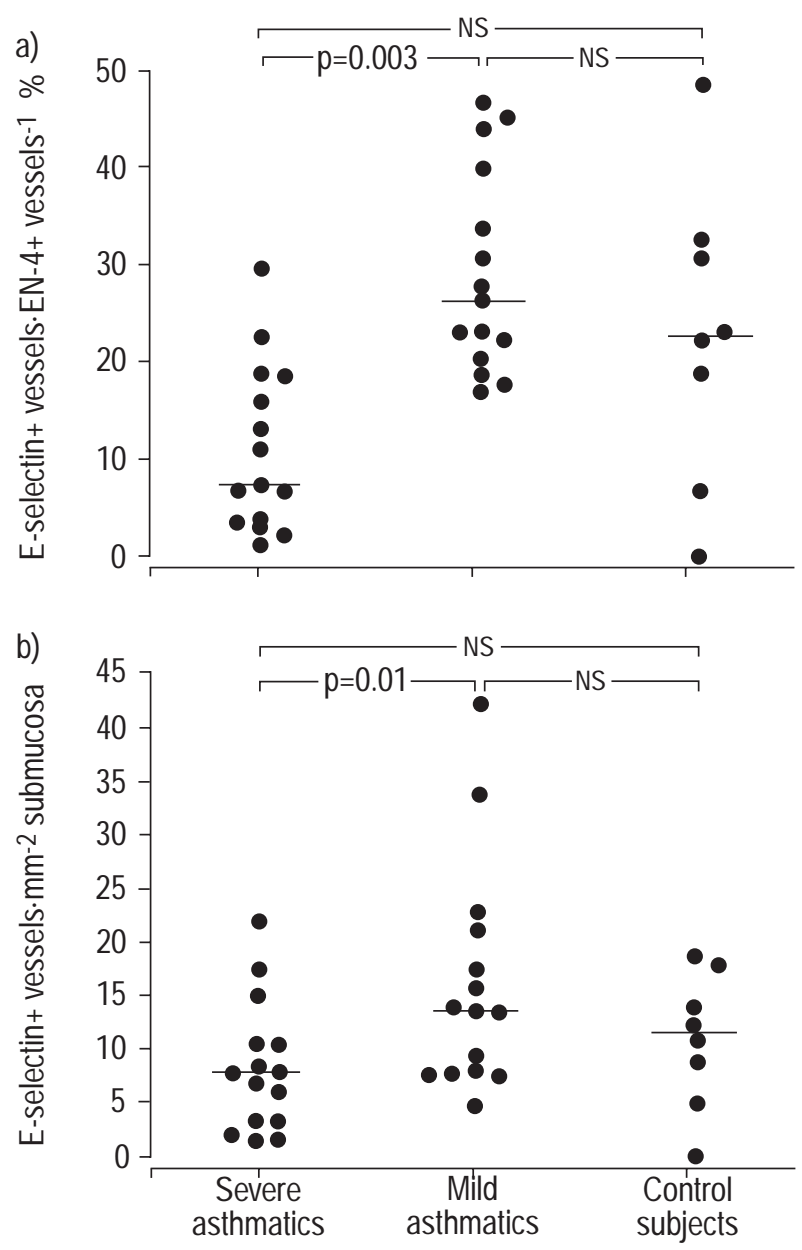

Fig. 4. - E-selectin expressed as percentage of the total number of the vessel marker, EN-4+, vessels (a) and as number of E-selectin+ vessels per square millimetre submucosa (b) in the biopsies of severe asthmatics, mild asthmatics and healthy nonatopic control subjects. Comparison between groups was by Mann-Whitney U-test with Bonferroni's correction. The horizontal lines represent the median values. NS: nonsignificant.

of asthma severity. Whilst the expression of ICAM-1 per vessel was not increased, the total number of vessels expressing this adhesion molecule was increased in severe asthma, providing a larger surface area for recruitment of cells into the mucosa. In contrast, no differences were found in the extent of VCAM-1 staining between severe asthma, mild asthma and control subjects. Together these findings point to an important role for the mucosal microvasculature in severe forms of asthma.

Because it is difficult to uncouple the attributes of more severe disease from those of glucocorticoid exposure, the authors did not study an additional group of well-controlled asthmatics on high doses of glucocorticoids. The primary goal of this and previous studies [11] was to investigate whether differences in VCAM expression could account for the differences in inflammatory cell profile between severe and mild asthmatics [11], and the authors therefore specifically selected patients who represented the two extremes of the disease spectrum. Previous studies have already shown that treatment of mild and moderately severe asthmatics with glucocorticoids is associated with a marked depletion of eosinophils and 
downregulation of T-lymphocyte activation with no differences in the expression of ICAM-1 and E-selectin [9].

The present study extends previous postmortem observations $[5,6]$ by showing that in living patients with severe asthma increased vascularity is associated with increased numbers of vessels expressing ICAM-1. In postmortem studies in cases of asthma death, the majority of patients were characterized by a long history of symptomatic asthma, frequent hospitalizations, persistent airflow obstruction, and had previously been treated with glucocorticoids [14]. This typical profile of severe asthma was found to be associated with an increase in smooth muscle, mucous gland hyperplasia, and basement membrane thickening, all probably a result of chronic airway inflammation $[1,2]$. Adding to the complexity of this remodelling process, increases in submucosal vessel density and vascular volume have been described [4-6]. Structural analyses of peripheral airways of asthmatic lungs have revealed that the proportion of the mucosa occupied by blood vessels is considerably higher in postmortem specimens from patients with asthma than in airways from nonasthmatic control subjects, which appeared to be particularly evident in those patients who had died of asthma [5]. In another study fatal asthma was characterized by an increase in both numbers of large vessels and total vessel area in the cartilaginous airways, suggesting enlargement of existing vessels [6]. The authors have not assessed large airway vessel size and area, because such measurements may be artificially distorted by tangential cutting of vessels and vasodilatation induced by $\beta_{2}$-agonists [19] or vasoactive mediators [20]. Furthermore, results from animal studies have shown that most of the airway narrowing is due to extravasation of plasma fluid rather than vascular congestion [21]. However, the increase in the numbers of mucosal vessels may in itself have two important pathophysiological consequences for the persistent airflow obstruction frequently observed in severe asthmatic patients. First, it is possible that bronchial vasocongestion and microvascular leakage induced by leukotriene and histamine may lead to transient increases in airway wall thickness [20]. Second, the abundant vascularity and associated ICAM-1 expression may enhance sequestration and adhesion of inflammatory cells $[7,22]$. The mucosal inflammation consequent upon it may further augment airway narrowing.

There is increasing evidence that angiogenesis occurs in asthmatic airways early in the process of airway remodelling [2, 12]. XUN and WILSON [12] found significantly higher numbers of vessels in bronchial biopsies from mild asthmatics $\left((\right.$ mean \pm SD $\left.) 738 \pm 150 \cdot \mathrm{mm}^{-2}\right)$ as compared with control subjects $\left(539 \pm 276 \cdot \mathrm{mm}^{-2}\right)$ using a collagen IV monoclonal antibody. By comparison with their observations, the current authors have found considerably lower numbers of vessels in all the subject groups with no increase in vascularity in mild disease compared with normal. Because the majority of vessels are located directly beneath the basement membrane, this discrepancy is most likely to be due to the fact that vessel numbers in their study were determined to a depth of $150 \mathrm{~mm}$ beneath the basement membrane in $4 \mu \mathrm{m}$ sections whereas in the current study the whole mucosa, including the nonvascular areas, of $2 \mathrm{~mm}$ sections was analysed.
The different monoclonal antibodies used in the various studies are unlikely to account for the differences in the results. Several endothelial-specific immunological markers, such as CD31, CD34, Ulex europaeus agglutinin I and factor VIII, also show positive staining for certain mesenchymal components and immune cells [23]. For instance CD34, a traditional vessel marker, also stains certain mesenchymal components, and as such is used in the diagnosis of lesions such as solitary fibrous tumour of the pleura and histiocytoma [23]. In the authors' experience EN-4 (CD31) also stains certain inflammatory cells, such as plasma cells and possibly mast cells. However, CD31 has been shown to be a highly specific and sensitive endothelial marker. Recently, it has been proposed that anti-CD31 immunostaining should be the standard for microvessel assessment in solid tumours [24]. Although type IV collagen antibody, used in the study of XUN and WILSON [12], is not an endothelial-specific marker, it is useful to outline the presence of basal lamina around vessels [23]. Most importantly, however, is that the interpretation of microvessel immunostaining has to rely on careful examination as well as the application of embedding techniques which provide an optimal morphology. To the authors' experience GMA-processing and paraffin embedding are superior to frozen tissue because they provide an excellent morphology allowing the clear distinction of vessels from other positively stained structural or inflammatory cells.

A further important finding in this study is the persistence of ICAM-1 expression on the endothelium despite treatment with high doses of inhaled and oral glucocorticoids. The authors cannot exclude the possibility that the anti-inflammatory effects of glucocorticoids may have influenced vascular expression of adhesion molecules [2527]. In a recent study, pretreatment of endothelial cells with glucocorticoids for $4 \mathrm{~h}$ prevented adhesion of neutrophils and diminished IL-1 and tumour necrosis factor (TNF)- $\alpha$-induced expression of ICAM- 1 and E-selectin in vitro [25]. However, long-term incubation of endothelial cells with glucocorticoids and TNF- $\alpha$ does not affect ICAM-1 expression [26, 27]. These observations are consistent with those made by MONTEForT et al. [9], who demonstrated that both ICAM-1 and E-selectin expression in bronchial biopsies remained unaltered after 6 weeks of treatment with high doses of topical glucocorticoids $\left(2,000 \mu \mathrm{g} \cdot \mathrm{day}^{-1}\right)$. These studies support the hypothesis that long-term administration of glucocorticoids does not directly downregulate the expression of these adhesion molecules in vivo [27].

Whilst the expression of ICAM-1 may not be upregulated per se, the increased density of vessels expressing ICAM-1, however, may enhance the influx of inflammatory cells and in particular activated T-cells in the airways from severe asthmatics and explain some of the recently described differences in the mucosal inflammatory profile between severe and mild asthma [11]. Because VLA-4 expression is restricted to eosinophils and lymphocytes, VCAM-1 has been implicated in the selective eosinophil diapedesis that characterizes atopic asthma [7]. However, in this study no differences were found in VCAM-1 expression or numbers of VLA-4+ cells between the three groups, thus failing to show that VCAM-1/VLA-4 interaction was an important determinant of cell recruitment. 
In contrast to ICAM-1, VCAM-1 and P-selectin, staining for E-selectin was weak in all groups with significantly lower numbers of vessels expressing E-selectin in severe asthma compared with mild asthma. In a previous study it has been shown that severe asthma is characterized by increased numbers of CD25+ T-cells and relatively low eosinophil counts [11]. Why sensitized T-cells specifically accumulate in the airways of these patients is uncertain. It has been shown that in vitro T-cell activation increases the avidity of VLA-4 and LFA-1 dependent binding to their ligands ICAM-1 and ICAM-1, respectively $[28,29]$. The low number of vessels expressing E-selectin may, however, have interfered with the tethering stage of eosinophil migration preceding eosinophil adhesion via ICAM-1, and partly account for the lower eosinophil counts in the airways of the majority of severe asthmatics [7, 8].

The consistent decrease in numbers of vessels expressing E-selectin found in severe asthma relative to mild disease may possibly be due to the inhibitory effects of high doses of glucocorticoids [25], involving nuclear factor (NF)- $\mathrm{KB}$ inhibition [30]. However, functional antagonism between the glucocorticoid receptor and NF- $\kappa \mathrm{B}$ has also been described in the transcriptional regulation of genes encoding for IL-8 and ICAM-1 [30], which has been shown in this and a previous study [31] to be insufficiently downregulated in severe asthma. Although the effect of glucocorticoids on adhesion molecule expression was not specifically addressed in this study, the results suggest that the mode of action of glucocorticoid varies significantly, depending on the target gene. Further investigations into the nature and dynamics of the inflammatory response in the presence of glucocorticoids are warranted because they may provide essential insights into the mechanism underlying the anti-inflammatory activity of these drugs.

In conclusion, the results of the study indicate that angiogenesis is a pathological feature of severe asthma that may partly explain why variable airflow limitation is more pronounced in this type of disease. They also show that in severe asthma there is an abundance of supepithelial vessels which continue to express intercellular adhesion molecule-1 despite glucocorticoid treatment, providing a mechanism by which inflammatory cell recruitment persists in these patients. The findings further indicate that expression of the various vascular adhesion molecules is differentially regulated. Further studies are required to elucidate the mechanisms regulating vascular adhesion molecule expression both in relation to asthma severity and treatment.

\section{References}

1. Djukanovic R, Roche WR, Wilson JW, et al. Mucosal inflammation in asthma. State of the art. Am Rev Respir Dis 1990; 142: 434-457.

2. Roche WR, Beasley R, Williams JH, Holgate ST. Subepithelial fibrosis in the bronchi of asthmatics. Lancet 1989; 1: 520-524.

3. Wilson JW, Xun Li, Pain MCF. Lack of airway distensibility in asthma. Am Rev Respir Dis 1993; 148: 806809.

4. Charan NB, Baile EM, Paré PD. Bronchial vascular congestion and angiogenesis. Eur Respir J 1997; 10: $1173-1180$.
5. Kuwano K, Bosken CH, Paré PD, Bai TR, Wiggs BR, Hogg JC. Small airways dimensions in asthma and chronic obstructive pulmonary disease. Am Rev Respir Dis 1993; 148: 1220-1225.

6. Carroll NG, Cooke C, James AL. Bronchial blood vessel dimensions in asthma. Am J Respir Crit Care Med 1997; 155: 689-695.

7. Smith CH, Barker JNW, Lee TH. Adhesion molecules in allergic inflammation. Am Rev Respir Dis 1993; 148: S75-S78.

8. Kunkel EJ, Jung U, Bullard DC, et al. Absence of traumainduced leukocyte rolling in mice deficient in both Pselectin and intercellular adhesion molecule 1. J Exp Med 1996; 183: 57-65.

9. Montefort S, Roche WR, Howarth PH, et al. Intercellular adhesion molecule-1 (ICAM-1) and endothelial leucocyte adhesion molecule-1 (ELAM-1) expression in the bronchial mucosa of normal and asthmatic subjects. Eur Respir J 1992; 5: 815-823.

10. Montefort S, Gratziou C, Goulding D, et al. Bronchial biopsy evidence for leukocyte infiltration and upregulation of leukocyte-endothelial adhesion molecules 6 hours after local allergen challenge of sensitized airways. J Clin lnvest 1994; 93: 1411-1421.

11. Vrugt B, Wilson S, Underwood J, et al. Mucosal inflammation in severe glucocorticoid-dependent asthma. Eur Respir J 1999; 13: 1245-1252.

12. Xun Li, Wilson JW. Increased vascularity of the bronchial mucosa in mild asthma. Am J Respir Crit Care Med 1997; 156: 229-233.

13. American Thoracic Society. Standards for the diagnosis and care of patients with chronic obstructive pulmonary disease (COPD) and asthma. Am Rev Respir Dis 1987; 136: $225-244$.

14. Woolcock AJ. Management of asthma in adults. In: Barnes PJ, Rodger IW, Thomson NC, eds. Asthma, basic mechanisms and clinical management. 2nd Edn. London, UK, Academic Press Ltd, 1992; 679-699.

15. Ryan G, Latimer KM, Dolovich J, Hargreave FE. Bronchial responsiveness to histamine: relationship to diurnal variation of peak flow rate, improvement after bronchodilator, and airway calibre. Thorax 1982; 37: 423-429.

16. Quanjer PH. Standardized lung function testing. Report Working Party Standardization of Lung Function Tests, European Community for Coal and Steel. Bull Europ Physiopath Respir 1983; 19: Suppl. 5, 1-95.

17. Djukanovic R, Wilson JW, Lai CKW, Holgate ST, Howarth PH. The safety aspects of fiberoptic bronchoscopy, bronchoalveolar lavage, and endobronchial biopsy in asthma. Am Rev Respir Dis 1991; 143: 772-777.

18. Britten KM, Howarth PH, Roche WR. Immunohistochemistry on resin sections: a comparison of resin embedding techniques for small mucosal biopsies. Biotech Histochem 1993; 68: 271-280.

19. Laitinen LA, Laitinen MA, Widdicombe JG. Dose-related effects of pharmacological mediators on tracheal vascular resistance in dogs. Br J Pharmacol 1987; 92: 703-709.

20. Church MK, Levi-Schaffer F. The human mast cell. $J$ Allergy Clin Immunol 1997; 99: 155-160.

21. Wagner EM, Mitzner W. Bronchial vascular engorgement and airflow obstruction. Chest 1995; 107: S103-S104.

22. MacNee W, Selby C. Neutrophil traffic in the lungs: role of haemodynamics, cell adhesion, and deformability. Thorax 1993; 48: 79-88.

23. Ordonez NG. Application of immunocytochemistry in the diagnosis of soft tissue sarcomas: a review and update. Adv Anatomic Pathol 1998; 2: 67-85. 
24. Vermeulen PB, Gasparini G, Fox SB, et al. Quantification of angiogenesis in solid tumors: an international consensus on the methodology and criteria of evaluation. Eur $J$ Cancer 1996; 14: 2474-2484.

25. Cronstein BN, Kimmel SC, Levin R1, Martinuk F. A mechanism for the anti-inflammatory effects of corticosteroids: the glucocorticoid receptor regulates leukocyte adhesion to endothelial cells and expression of endothelial-leukocyte adhesion molecule I and intercellular adhesion molecule 1. Proc Natl Acad Sci USA 1992; 89: 9991-9995.

26. Bochner BS, Rutledge BK, Schleimer RP. Interleukin1 production by human lung tissue II. Inhibition by anti-inflammatory steroids. J Immunol 1987; 139: 23032307.
27. Schleimer RP. Effects of glucocorticosteroids on inflammatory cells relevant to their therapeutic applications in asthma. Am Rev Respir Dis 1990; 141: S59-S69.

28. Wysocki J, Issekutz TB. Effect of T cell activation on lymphocyte-endothelial adherence and the role of VLA-4 in the rat. Cell lmmunol 1992; 140: 420-431.

29. Dustin ML, Springer TA. T-cell receptor cross-linking transiently stimulates adhesiveness through LFA-1. Nature 1989; 341: 619-624.

30. Barnes PJ, Adcock IM. Transcription factors and asthma. Eur Respir J 1998; 12: 221-234.

31. Shute JK, Vrugt B, Lindley IJD, et al. Free and complexed interleukin- 8 in blood and bronchial mucosa in asthma. Am J Respir Crit Care Med 1997; 155: 18771883. 